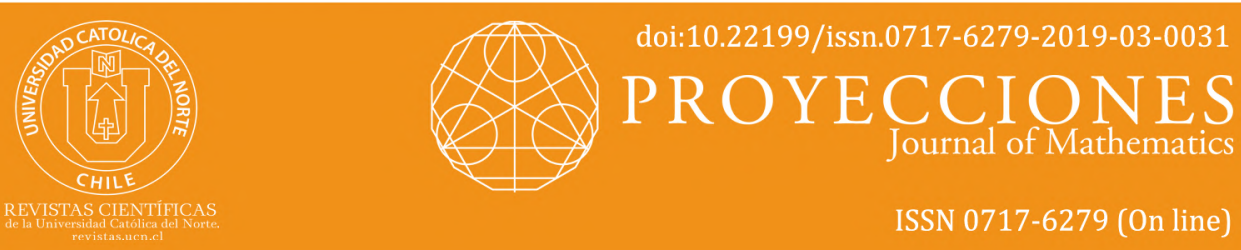

\title{
On a new class of generalized difference sequence spaces of fractional order defined by modulus function
}

T. Yaying* iD orcid.org/0000-0003-3435-8417

*Dera Natung Govt. College, Dept. of Mathematics, Itanagar, AR, India.

tajayaying20@gmail.com

Received: April 2018 | Accepted: October 2018

\section{Abstract:}

Recently Baliarsingh and Dutta [11, 12] introduced the fractional difference operator $\Delta^{\alpha}$, defined by $\Delta^{\alpha}\left(x_{k}\right)=\sum_{i=0}^{\infty}(-1)^{i} \frac{\Gamma(\alpha+1)}{i ! \Gamma(\alpha-i+1)} x_{k+i}$ and defined new classes of generalized difference sequence spaces of fractional order $X\left(\Gamma, \Delta^{\alpha}, u\right)$ where $X=\left\{\ell_{\infty}, c, c_{0}\right\}$. More recently, Kadak [21] studied strongly Cesàro and statistical difference sequence space of fractional order involving lacunary sequences using the fractional difference operator $\Delta_{v}^{\alpha}$ defined by $\Delta_{v}^{\alpha}\left(x_{k}\right)=\sum_{i=0}^{\infty}(-1)^{i} \frac{\Gamma(\alpha+1)}{i ! \Gamma(\alpha-i+1)} v_{k+i} x_{k+i}$, where $v=\left(v_{k}\right)$ is any fixed sequence of positive real or complex numbers.

Following Baliarsingh and Dutta [11, 12] and Kadak [21], we introduce paranormed difference sequence spaces $N_{\theta}\left(\Delta_{v}^{\alpha}, f, p\right)$ and $S_{\theta}\left(\Delta_{v}^{\alpha}, f, p\right)$ of fractional order involving lacunary sequence, $\theta$ and modulus function, $f$. We investigate topological structures of these spaces and examine various inclusion relations.

Keywords: Difference operator $\Delta_{v}^{\alpha}$; Paranormed sequence; Lacunary sequence;

MSC (2000): 46A45, 40A35, 46A80.

\section{Cite this article as (IEEE citation style):}

T. Yaying, "On a new class of generalized difference sequence spaces of fractional order defined by modulus function", Proyecciones (Antofagasta, On line), vol. 38, no. 3, pp. 485-497, Aug. 2019, doi: 10.22199/issn.0717-6279-2019-03-0031. [Accessed dd-mm-yyyy].

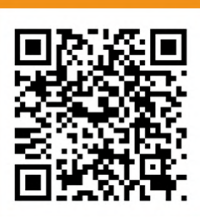

Article copyright: (c) 2019 Taja Yaying. This is an open access article distributed under the terms of the Creative Commons Licence, which permits unrestricted use and distribution provided the original author and source are credited. 


\section{Introduction}

Throughout $\omega$ will denote the space of all real valued sequences and any subspace of $\omega$ is called sequence space. $\ell_{\infty}, c$ and $c_{0}$ will denote the spaces of bounded, convergent and null sequences, respectively. These spaces are Banach spaces normed by $\|x\|_{\infty}=\sup _{k}\left|x_{k}\right|$.

The notion of difference sequence spaces was first determined by Kizmaz [1]. Later on, the notion was generalized by Et and Colak [2]. Also Et and Esi [3] generalized the sequence spaces to the sequence spaces as given below:

Let $m$ be a non negative integer, then

$$
\Delta_{v}^{m}(X)=\left\{x=\left(x_{k}\right): \Delta_{v}^{m}(x) \in X\right\} \text { for } X \in\left\{\ell_{\infty}, c, c_{0}\right\},
$$

where $\Delta_{v}^{m}(x)=\left(\Delta_{v}^{m-1}\left(x_{k}\right)-\Delta_{v}^{m-1}\left(x_{k+1}\right)\right), \Delta_{v}^{0}(x)=\left(v_{k} x_{k}\right)$ and $\Delta_{v}^{m}\left(x_{k}\right)=$ $\sum_{i=0}^{m}(-1)^{i}\left(\begin{array}{c}m \\ i\end{array}\right) v_{k+i} x_{k+i}$.

These spaces are Banach spaces with norm defined by

$$
\|x\|_{\Delta}=\sum_{i=1}^{m}\left|v_{i} x_{i}\right|+\sup _{k}\left|\Delta_{v}^{m}\left(x_{k}\right)\right| .
$$

Furthermore, generalized difference sequence space was studied by Et and Basarir [4], Malkowsky and Parashar [5], Et and Tripathy [22], Colak [6], and many others.

The notion of statistical convergence was independently introduced by Fast [14] and Schoenberg [15]. The concept lies on the asymptotic density of the subset $E$ of natural number $\mathbf{N}$. A subset $E$ of $\mathbf{N}$ is said to have asymptotic density $\delta(E)$, if $\delta(E)=\lim _{n \rightarrow \infty} \frac{1}{n} \sum_{k=1}^{n} \chi_{E}(k)$ exists, where $\chi_{E}$ is the characteristic function of $E$.

A sequence $\left(x_{n}\right)$ is said to be statistically convergent to $L$ if for every $\varepsilon>0$

$$
\lim _{n \rightarrow \infty}\left|\left\{k \in \mathbf{N}:\left|x_{k}-L\right| \geq \varepsilon\right\}\right|=0,
$$

where $|E|$ denotes the cardinality of the set $E$. In this case, we write $S-\lim x_{k}=L$ or $x_{k} \rightarrow L(S)$. 
Let $\theta=\left(k_{r}\right)$ be the sequence of positive integers such that $k_{r}=0$, $0<k_{r}<k_{r+1}$ and $h_{r}=k_{r}-k_{r-1} \rightarrow 0$ as $r \rightarrow \infty$. Then $\theta$ is called lacunary sequence. The intervals determined by $\theta$ will be denoted by $I_{r}=\left(k_{r-1}, k_{r}\right]$ and the ratio $\frac{k_{r}}{k_{r-1}}$ will be denoted by $q_{r}$. Freedman et. Al [34] introduced the sequence space $N_{\theta}$ given by

$$
N_{\theta}=\left\{\left(x_{k}\right) \in \omega: h_{r}^{-1} \sum_{k \in I_{r}}\left|x_{k}-L\right| \rightarrow 0, \text { for some } L\right\} ;
$$

and showed that the space $N_{\theta}$ is a $B K$ space with the norm defined by

$$
\|x\|_{\theta}=\sup _{r}\left(h_{r}^{-1} \sum_{I_{r}}\left|x_{k}\right|\right) \text {. }
$$

A modulus is a function $f:[0, \infty) \rightarrow[0, \infty)$ such that

(i) $f(x)=0$ if and only if $x=0$;

(ii) $f(x+y) \leq f(x)+f(y)$;

(iii) $f$ is increasing;

(iv) $f$ is continuous from right at 0 .

The notion of modulus function was introduced by Nakano [17] followed by Ruckle [19], Maddox [18], Tripathy and Chandra [25] and many others, to construct various sequence spaces. The following inequality (see [20]) will be used throughout in this article:

$$
\left|a_{k}+b_{k}\right|^{p_{k}} \leq C\left(\left|a_{k}\right|^{p_{k}}+\left|b_{k}\right|^{p_{k}}\right) ;
$$

where $a_{k}, b_{k} \in \mathbf{C}, 0<p_{k} \leq \sup p_{k}=H, C=\max \left(1,2^{H-1}\right)$.

Proposition 1.1. [32] Let $f$ be a modulus function and let $0<\delta<1$. Then for each $x \geq \delta$ we have $f(x) \leq 2 f(1) \delta^{-1} x$.

\section{Fractional Difference Operator and Generalized Difference Sequence Space of Fractional Order}

Let $\Gamma(m)$ be the Gamma function of a real number $m$ and $m \notin\{0,-1,-2, \ldots\}$. By definition, it can be expressed as an improper integral

$$
\Gamma(m)=\int_{0}^{\infty} e^{-x} x^{m-1} d x
$$


Recently, Baliarsingh and Dutta $[11,12]$ have introduced the generalized difference operator $\Delta^{\alpha}$, for a positive fraction $\alpha$ as follows:

$$
\Delta^{\alpha}\left(x_{k}\right)=\sum_{i=0}^{\infty}(-1)^{i} \frac{\Gamma(\alpha+1)}{i ! \Gamma(\alpha-i+1)} x_{k+i} .
$$

In particular, we have,

(i) $\Delta^{\frac{1}{2}}\left(x_{k}\right)=x_{k}-\frac{1}{2} x_{k+1}-\frac{1}{8} x_{k+2}-\frac{1}{16} x_{k+3}-\frac{5}{128} x_{k+4}-\ldots$

(ii) $\Delta^{\frac{-1}{2}}\left(x_{k}\right)=x_{k}+\frac{1}{2} x_{k+1}+\frac{3}{8} x_{k+2}+\frac{5}{16} x_{k+3}+\frac{35}{128} x_{k+4}+\ldots$

(iii) $\Delta^{\frac{2}{3}}\left(x_{k}\right)=x_{k}-\frac{2}{3} x_{k+1}-\frac{1}{9} x_{k+2}-\frac{4}{81} x_{k+3}-\frac{7}{243} x_{k+4}-\ldots$

Baliarsingh [10] defined the spaces $X\left(\Gamma, \Delta^{\alpha}, u\right)$ for $X \in\left\{\ell_{\infty}, c, c_{0}\right\}$ using the fractional difference operator $\Delta^{\alpha}$ and studied their topological properties and obtained their $\alpha, \beta$, and $\gamma$ duals.

The studies on generalized difference sequence spaces of fractional order was extended by Baliarsingh and Dutta [12, 29], Kadak and Baliarsingh [13], Serkan and Osman [30], Hasan Furkan [33], Kadak [21] and others.

Kadak in [21] determined a new classes of fractional difference sequence spaces $\Delta_{v}^{\alpha}(X)$ as follows:

$$
\Delta_{v}^{\alpha}(X)=\left\{x=\left(x_{k}\right) \in \omega: \Delta_{v}^{\alpha}(X) \in X\right\}
$$

where $\Delta_{v}^{\alpha}\left(x_{k}\right)=\sum_{i=0}^{\infty}(-1)^{i} \frac{\Gamma(\alpha+1)}{i ! \Gamma(\alpha-i+1)} v_{k+i} x_{k+i}$ and $v=\left(v_{k}\right)$ is a sequence of positive real numbers. Using the fractional difference operator $\Delta_{v}^{\alpha}$, he defined strongly Cesàro and statistical difference sequence spaces of fractional order involving lacunary sequence, $\theta$ and arbitrary sequence $p=\left(p_{r}\right)$ of positive real numbers.

Theorem 2.1. [10]

(a) For proper fraction, $\Delta^{\alpha}: \omega \rightarrow \omega$ is a linear operator.

(b) For $\alpha, \beta>0, \Delta^{\alpha}\left(\Delta^{\beta}\left(x_{k}\right)\right)=\Delta^{\alpha+\beta}\left(x_{k}\right)$ and $\Delta^{\alpha}\left(\Delta^{-\alpha}\left(x_{k}\right)\right)=x_{k}$.

The main objective of this article is to introduce generalized paranormed difference sequence spaces $N_{\theta}\left(\Delta_{v}^{\alpha}, f, p\right)$ and $S_{\theta}\left(\Delta_{v}^{\alpha}, f, p\right)$ of fractional order involving lacunary sequence, $\theta$ and modulus function, $f$ and to investigate topological structures of these spaces and examine various inclusion relations. 


\section{Main Results}

By using the fractional difference operator $\Delta_{v}^{\alpha}$, we introduce some new generalized difference sequence spaces $N_{\theta}\left(\Delta_{v}^{\alpha}, f, p\right), N_{\theta}^{0}\left(\Delta_{v}^{\alpha}, f, p\right)$ and $N_{\theta}^{\infty}\left(\Delta_{v}^{\alpha}, f, p\right)$ involving lacunary sequence, $\theta$ and modulus function, $f$ as follows:

$$
\begin{gathered}
N_{\theta}\left(\Delta_{v}^{\alpha}, f, p\right)=\left\{x=\left(x_{k}\right) \in \omega: \lim _{r \rightarrow \infty} h_{r}^{-1} \sum_{k \in I_{r}} f\left(\left|\Delta_{v}^{\alpha} x_{k}-L\right|\right)^{p_{k}}=0, \text { for some } L\right\} ; \\
N_{\theta}^{0}\left(\Delta_{v}^{\alpha}, f, p\right)=\left\{x=\left(x_{k}\right) \in \omega: \lim _{r \rightarrow \infty} h_{r}^{-1} \sum_{k \in I_{r}} f\left(\left|\Delta_{v}^{\alpha} x_{k}\right|\right)^{p_{k}}=0\right\} ; \\
N_{\theta}^{\infty}\left(\Delta_{v}^{\alpha}, f, p\right)=\left\{x=\left(x_{k}\right) \in \omega: \lim _{r \rightarrow \infty} h_{r}^{-1} \sum_{k \in I_{r}} f\left(\left|\Delta_{v}^{\alpha} x_{k}\right|\right)^{p_{k}}<\infty\right\} ;
\end{gathered}
$$

where $\Delta_{v}^{\alpha}\left(x_{k}\right)=\sum_{i=0}^{\infty}(-1)^{i} \frac{\Gamma(\alpha+1)}{i ! \Gamma(\alpha-i+1)} v_{k+i} x_{k+i}$ and $v=\left(v_{k}\right)$ is a fixed sequence of positive real numbers.

Theorem 3.1. The sequence spaces $N_{\theta}\left(\Delta_{v}^{\alpha}, f, p\right), N_{\theta}^{0}\left(\Delta_{v}^{\alpha}, f, p\right)$ and $N_{\theta}^{\infty}\left(\Delta_{v}^{\alpha}, f, p\right)$ are linear spaces.

Proof. We shall prove for $N_{\theta}^{0}\left(\Delta_{v}^{\alpha}, f, p\right)$. Let $x, y \in N_{\theta}^{0}\left(\Delta_{v}^{\alpha}, f, p\right)$ and $\alpha^{\prime}$ and $\beta^{\prime}$ be scalars. Then there exist positive numbers $M_{\alpha^{\prime}}$ and $N_{\beta^{\prime}}$ such that $\left|\alpha^{\prime}\right| \leq M_{\alpha^{\prime}}$ and $\left|\beta^{\prime}\right| \leq N_{\beta^{\prime}}$. Since $f$ is subadditive and $\Delta_{v}^{\alpha}$ is linear, $\mathrm{h}_{r}^{-1} \sum_{k \in I_{r}} f\left(\mid \Delta_{v}^{\alpha}\left(\alpha^{\prime} x_{k}+\beta^{\prime} y_{k} \mid\right)^{p_{k}} \leq h_{r}^{-1} \sum_{k \in I_{r}}\left[f\left(\left|\alpha^{\prime}\right|\left|\Delta_{v}^{\alpha} x_{k}\right|\right)+f\left(\left|\beta^{\prime}\right|\left|\Delta_{v}^{\alpha} y_{k}\right|\right)\right]^{p_{k}}\right.$ $\leq C\left(M_{\alpha^{\prime}}\right)^{H} h_{r}^{-1} \sum_{k \in I_{r}} f\left(\left|\Delta_{v}^{\alpha} x_{k}\right|\right)^{p_{k}}+C\left(N_{\beta^{\prime}}\right)^{H} h_{r}^{-1} \sum_{k \in I_{r}} f\left(\left|\Delta_{v}^{\alpha} y_{k}\right|\right)^{p_{k}}$ $\rightarrow 0$ as $r \rightarrow \infty$. This proves the linearity of $N_{\theta}^{0}\left(\Delta_{v}^{\alpha}, f, p\right)$.

Theorem 3.2. $N_{\theta}^{0}\left(\Delta_{v}^{\alpha}, f, p\right)$ is a paranormed sequence space paranormed by

$$
g(x)=\sup _{r}\left(h_{r}^{-1} \sum_{k \in I_{r}} f\left(\left|\Delta_{v}^{\alpha} x_{k}\right|\right)^{p_{k}}\right)^{\frac{1}{M}} .
$$

Proof. Clearly $g(\theta)=0$ and $g(x)=g(-x)$ for all $x \in N_{\theta}^{0}\left(\Delta_{v}^{\alpha}, f, p\right)$. Using the linearity of $\Delta_{v}^{\alpha}$, definition of $f$ and Minkowski's inequality, it is not difficult to show that $g(x+y) \leq g(x)+g(y)$, for any two sequences $x, y \in N_{\theta}^{0}\left(\Delta_{v}^{\alpha}, f, p\right)$. 
It remains to show the continuity of the scalar multiplication. Let $\lambda$ be any scalar. By definition of modulus $f$, we have

$$
g(\lambda x)=\sup _{r}\left(h_{r}^{-1} \sum_{k \in I_{r}} f\left(\left|\Delta_{v}^{\alpha} \lambda x_{k}\right|\right)^{p_{k}}\right)^{\frac{1}{M}} \leq N_{\lambda}^{\frac{H}{M}} g(x),
$$

where $N_{\lambda}$ is a positive number such that $|\lambda| \leq N_{\lambda}$ and $H=\sup p_{k}$. Now, let $\lambda \rightarrow 0$ and $x=\left(x_{k}\right)$ be fixed with $g(x) \neq 0$, then for $|\lambda|<1$,

$$
h_{r}^{-1} \sum_{k \in I_{r}} f\left(\left|\Delta_{v}^{\alpha} \lambda x_{k}\right|\right)^{p_{k}}<\varepsilon, \text { for } i>i_{0} .
$$

Also, for $1<i<i_{0}$, taking $\lambda$ small enough, continuity of $f$ implies that

$$
h_{r}^{-1} \sum_{k \in I_{r}} f\left(\left|\Delta_{v}^{\alpha} \lambda x_{k}\right|\right)^{p_{k}}<\varepsilon .
$$

Thus, $g(\lambda x) \rightarrow 0$ as $\lambda \rightarrow 0$. This completes the proof.

Theorem 3.3. Let $f$ be a modulus function, then

$$
N_{\theta}^{0}\left(\Delta_{v}^{\alpha}, f, p\right) \subset N_{\theta}\left(\Delta_{v}^{\alpha}, f, p\right) \subset N_{\theta}^{\infty}\left(\Delta_{v}^{\alpha}, f, p\right) .
$$

Proof. The first inclusion is obvious. We provide the proof of the second inclusion.

Let $x \in N_{\theta}\left(\Delta_{v}^{\alpha}, f, p\right)$. By definition of $f$, we have, $\mathrm{h}_{r}^{-1} \sum_{k \in I_{r}} f\left(\left|\Delta_{v}^{\alpha} x_{k}\right|\right)^{p_{k}}=$ $h_{r}^{-1} \sum_{k \in I_{r}} f\left(\left|\Delta_{v}^{\alpha} x_{k}-L+L\right|\right)^{p_{k}}$ $\leq C h_{r}^{-1} \sum_{k \in I_{r}} f\left(\left|\Delta_{v}^{\alpha} x_{k}-L\right|\right)^{p_{k}}+C h_{r}^{-1} \sum_{k \in I_{r}} f(|L|)^{p_{k}}$.

Now, there exist a positive integer $K_{L}$ such that $|L| \leq K_{L}$. Hence, we have,

$$
h_{r}^{-1} \sum_{k \in I_{r}} f\left(\left|\Delta_{v}^{\alpha} x_{k}\right|\right)^{p_{k}} \leq C h_{r}^{-1} \sum_{k \in I_{r}} f\left(\left|\Delta_{v}^{\alpha} x_{k}-L\right|\right)^{p_{k}}+C\left(K_{L} f(1)\right)^{H} .
$$

This proves the result.

Theorem 3.4. If $f, f_{1}, f_{2}$ be modulus functions and $X \in\left\{N_{\theta}, N_{\theta}^{0}, N_{\theta}^{\infty}\right\}$, then

(i) $X\left(\Delta_{v}^{\alpha}, f, p\right) \subset X\left(\Delta_{v}^{\alpha}, f \cdot f_{1}, p\right)$,

(ii) $X\left(\Delta_{v}^{\alpha}, f_{1}, p\right) \cap X\left(\Delta_{v}^{\alpha}, f_{2}, p\right) \subset X\left(\Delta_{v}^{\alpha}, f_{1}+f_{2}, p\right)$. 


\section{Proof.}

(i) We shall prove for $N_{\theta}^{0}\left(\Delta_{v}^{\alpha}, f, p\right)$. Let $\varepsilon>0$ and choose $0<\delta<1$ such that $f(t)<\varepsilon$ for $0 \leq t \leq \delta$. We write $y_{k}=f_{1}\left(\left|\Delta_{v}^{\alpha} x_{k}\right|\right)$ and consider

$$
\sum_{k \in I_{r}} f\left(y_{k}\right)^{p_{k}}=\sum_{1} f\left(y_{k}\right)^{p_{k}}+\sum_{2} f\left(y_{k}\right)^{p_{k}}
$$

where the first summation runs over $y_{k} \leq \delta$ and the second summation runs over $y_{k}>\delta$. Since $f$ is continuous, we have

$$
\sum_{1} f\left(y_{k}\right)^{p_{k}}<h_{r} \varepsilon^{H}
$$

Also,

$$
y_{k}<\frac{y_{k}}{\delta} \leq 1+\frac{y_{k}}{\delta}
$$

Hence, by using Proposition 1.1, we can write,

$$
h_{r}^{-1} \sum_{2} f\left(y_{k}\right)^{p_{k}} \leq \max \left(1,\left(2 f(1) \delta^{-1}\right)^{H}\right) h_{r}^{-1} \sum_{k \in I_{r}} y_{k}
$$

Using equations 3.1 and 3.2 , we get $N_{\theta}^{0}\left(\Delta_{v}^{\alpha}, f, p\right) \subset N_{\theta}^{0}\left(\Delta_{v}^{\alpha}, f \cdot f_{1}, p\right)$

(ii) The proof of (ii) follows from the inequality

$$
\left(f_{1}+f_{2}\right)\left(\left|\Delta_{v}^{\alpha} x_{k}\right|\right)^{p_{k}} \leq C f_{1}\left(\left|\Delta_{v}^{\alpha} x_{k}\right|\right)^{p_{k}}+C f_{2}\left(\left|\Delta_{v}^{\alpha} x_{k}\right|\right)^{p_{k}}
$$

The following result is an immediate consequence of Theorem 3.4 (i).

Corollary 3.5. Let $f$ be a modulus function. Then $X\left(\Delta_{v}^{\alpha}, p\right) \subset X\left(\Delta_{v}^{\alpha}, f, p\right)$ where $X \in\left\{N_{\theta}, N_{\theta}^{0}, N_{\theta}^{\infty}\right\}$.

Theorem 3.6. Let $0<p_{k}<q_{k}$ and $\left(\frac{q_{k}}{p_{k}}\right)$ be bounded then $X\left(\Delta_{v}^{\alpha}, f, q\right) \subset$ $X\left(\Delta_{v}^{\alpha}, f, p\right)$.

Proof. The proof of the theorem is easy and hence omitted. 


\section{Lacunary statistical convergence of fractional order de- fined by modulus function}

In this section we introduce generalized lacunary statistical convergence of fractional order defined by a modulus function as follows:

$S_{\theta}\left(\Delta_{v}^{\alpha}, f, p\right)=\left\{x=\left(x_{k}\right) \in \omega: \lim _{r \rightarrow \infty} h_{r}^{-1}\left|\left\{k \in I_{r}: f\left(\left|\Delta_{v}^{\alpha} x_{k}-L\right|\right)^{p_{k}} \geq \varepsilon\right\}\right|=0\right.$,

for some $L\}$.

When $p=\left(p_{k}\right)=1$, we shall denote $S_{\theta}\left(\Delta_{v}^{\alpha}, f, p\right)$ by $S_{\theta}\left(\Delta_{v}^{\alpha}, f\right)$.

Note that when $f(x)=x, p=\left(p_{k}\right)=1$, then $S_{\theta}\left(\Delta_{v}^{\alpha}, f, p\right)$ reduces to $S_{\theta}\left(\Delta_{v}^{\alpha}\right)$ as studied by Kadak [21]. When $f(x)=x, p=\left(p_{k}\right)=1$ and $\alpha=m \in \mathbf{N}$, then $S_{\theta}\left(\Delta_{v}^{\alpha}, f, p\right)$ reduces to $S_{\theta}\left(\Delta_{v}^{m}\right)$ as studied by Et [28]. The class of lacunary convergence has been studied from different aspects by Fridy and Orhan [31], Tripathy and Baruah [24], Tripathy and Mahanta [23], Tripathy and Dutta [26], Tripathy et al. [27] and many others.

Theorem 4.1. Let $\theta$ be a lacunary sequence. Then $S\left(\Delta_{v}^{\alpha}, f\right) \subset S_{\theta}\left(\Delta_{v}^{\alpha}, f\right)$, if $\liminf q_{r}>1$.

Proof. Let liminf $q_{r}>1$, then there exist a $\delta>0$ such that $1+\delta \leq q_{r}$, for sufficiently large $r$. Since $h_{r}=k_{r}-k_{r-1}$, which implies that $\frac{h_{r}}{k_{r}} \geq \frac{\delta}{1+\delta}$.

Let $x \in S\left(\Delta_{v}^{\alpha}, f\right)$. Then for $\varepsilon>0$,

$$
\begin{aligned}
\frac{1}{k_{r}}\left|\left\{k \leq k_{r}: f\left(\left|\Delta_{v}^{\alpha} x_{k}-L\right|\right) \geq \varepsilon\right\}\right| & \geq \frac{1}{k_{r}}\left|\left\{k \in I_{r}: f\left(\left|\Delta_{v}^{\alpha} x_{k}-L\right|\right) \geq \varepsilon\right\}\right| \\
& \geq \frac{\delta}{1+\delta} h_{r}^{-1}\left|\left\{k \in I_{r}: f\left(\left|\Delta_{v}^{\alpha} x_{k}-L\right|\right) \geq \varepsilon\right\}\right| ;
\end{aligned}
$$

This esthablishes the result.

Theorem 4.2. Let $\theta$ be a lacunary sequence. Then $S_{\theta}\left(\Delta_{v}^{\alpha}, f\right) \subset S\left(\Delta_{v}^{\alpha}, f\right)$, if $\lim \sup q_{r}<\infty$.

Proof. Let $\lim \sup q_{r}<\infty$, then there is a $K>0$ such that $q_{r}<K$, for all $r$. Let $x \in S_{\theta}\left(\Delta_{v}^{\alpha}, f\right)$ and let $\tau_{r}=\left|\left\{k \in I_{r}: f\left(\left|\Delta_{v}^{\alpha} x_{k}-L\right|\right) \geq \varepsilon\right\}\right|$.

Now by definition, for $\varepsilon>0$ there is an integer $r_{0}$ such that

$$
h_{r}^{-1} \tau_{r}<\varepsilon \text { for all } r>r_{0} .
$$


Now let $\gamma=\max \left\{\tau_{r}: 1 \leq r \leq r_{0}\right\}$ and let $n$ be any integer satisfying $k_{r-1}<$ $n \leq k_{r}$; then we can write,

$$
\begin{aligned}
\frac{1}{n}\left|\left\{k \leq n: f\left(\left|\Delta_{v}^{\alpha} x_{k}-L\right|\right) \geq \varepsilon\right\}\right| & \leq \frac{1}{k_{r}-1}\left|\left\{k \leq k_{r}: f\left(\left|\Delta_{v}^{\alpha} x_{k}-L\right|\right) \geq \varepsilon\right\}\right| \\
& =\frac{1}{k_{r-1}}\left\{\tau_{1}+\tau_{2}+\ldots+\tau_{r_{0}}+\tau_{r_{0}+1}+\ldots+\tau_{r}\right\} \\
& \leq \frac{\gamma}{k_{r-1}} r_{0}+\frac{1}{k_{r-1}}\left\{h_{r_{0}+1} \frac{\tau_{r_{0}+1}}{h_{r_{0}+1}+\ldots+h_{r}}+\ldots \frac{\tau_{r}}{h_{r}}\right\} \\
& \leq \frac{\gamma}{k_{r-1}} r_{0}+\frac{1}{k_{r-1}}\left(\sup _{r<r_{0}} \frac{\tau_{r}}{h_{r}}\right)\left(h_{r_{0}+1}+\ldots+h_{r}\right) \\
& \left.\leq \frac{\gamma}{k_{r-1}} r_{0}+\varepsilon \frac{k_{r}-k_{r_{0}}}{k_{r-1}} \quad \text { (using equation } 4.1\right) \\
& \leq \frac{\gamma}{k_{r-1}} r_{0}+\varepsilon q_{r} \\
& \leq \frac{\gamma}{k_{r-1}} r_{0}+\varepsilon K .
\end{aligned}
$$

This establishes the result.

Following result is the direct consequence of theorems 4.1 and 4.2 .

Corollary 4.3. Let $\theta$ be a lacunary sequence. Then $S\left(\Delta_{v}^{\alpha}, f\right)=S_{\theta}\left(\Delta_{v}^{\alpha}, f\right)$, if $1<\liminf q_{r} \leq \limsup q_{r}<\infty$.

Theorem 4.4. Let $f$ be a modulus function and $H=\sup _{k} p_{k}$. Then $N_{\theta}\left(\Delta_{v}^{\alpha}, f, p\right) \subset S_{\theta}\left(\Delta_{v}^{\alpha}\right)$.

Proof. Let $x \in N_{\theta}\left(\Delta_{v}^{\alpha}, f, p\right)$ and $\varepsilon>0$ be given. Then,

$$
\begin{gathered}
h_{r}^{-1} \sum_{k \in I_{r}} f\left(\left|\Delta_{v}^{\alpha} x_{k}-L\right|\right)^{p_{k}}=h_{r}^{-1} \sum_{\substack{k \in I_{r} \\
\left|\Delta_{v}^{\alpha} x_{k}-L\right| \geq \varepsilon}} f\left(\left|\Delta_{v}^{\alpha} x_{k}-L\right|\right)^{p_{k}} \\
+h_{r}^{-1} \sum_{\substack{k \in I_{r} \\
\left|\Delta_{v}^{\alpha} x_{k}-L\right|<\varepsilon}} f\left(\left|\Delta_{v}^{\alpha} x_{k}-L\right|\right)^{p_{k}} \\
\geq h_{r}^{-1} \sum_{\substack{k \in I_{r} \\
\left|\Delta_{v}^{\alpha} x_{k}-L\right| \geq \varepsilon}} f\left(\left|\Delta_{v}^{\alpha} x_{k}-L\right|\right)^{p_{k}} \\
\geq h_{r}^{-1} \sum_{k \in I_{r}} f(\varepsilon)^{p_{k}} \\
\geq h_{r}^{-1} \sum_{k \in I_{r}} \min \left(f(\varepsilon)^{\inf p_{k}}, f(\varepsilon)^{H}\right) \\
\geq h_{r}^{-1}\left|\left\{k \in I_{r}:\left|\Delta_{v}^{\alpha} x_{k}-L\right| \geq \varepsilon\right\}\right| \min \left(f(\varepsilon)^{\inf p_{k}}, f(\varepsilon)^{H}\right)
\end{gathered}
$$


Taking the limit as $r \rightarrow \infty$, we have

$$
\begin{gathered}
\lim _{r \rightarrow \infty} h_{r}^{-1}\left|\left\{k \in I_{r}:\left|\Delta_{v}^{\alpha} x_{k}-L\right| \geq \varepsilon\right\}\right| \\
\leq \frac{1}{\min \left(f(\varepsilon)^{\inf p_{k}}, f(\varepsilon)^{H}\right)} \lim _{r \rightarrow \infty} h_{r}^{-1} \sum_{k \in I_{r}} f\left(\left|\Delta_{v}^{\alpha} x_{k}-L\right|\right)^{p_{k}}=0 .
\end{gathered}
$$

This establishes the result.

Theorem 4.5. Let $f$ be bounded and $0<h=\inf p_{k} \leq p_{k} \leq \sup p_{k}=$ $H<\infty$. Then $S_{\theta}\left(\Delta_{v}^{\alpha}\right) \subset N_{\theta}\left(\Delta_{v}^{\alpha}, f, p\right)$.

Proof. Since $f$ is bounded, there exists some $K$ such that $f(x)<K$ for all $x \geq 0$. Now,

$$
\begin{gathered}
h_{r}^{-1} \sum_{k \in I_{r}} f\left(\left|\Delta_{v}^{\alpha} x_{k}-L\right|\right)^{p_{k}}=h_{r}^{-1} \sum_{\substack{k \in I_{r} \\
\left|\Delta_{v}^{\alpha} x_{k}-L\right| \geq \varepsilon}} f\left(\left|\Delta_{v}^{\alpha} x_{k}-L\right|\right)^{p_{k}} \\
+h_{r}^{-1} \sum_{\substack{k \in I_{r} \\
\left|\Delta_{v}^{\alpha} x_{k}-L\right|<\varepsilon}} f\left(\left|\Delta_{v}^{\alpha} x_{k}-L\right|\right)^{p_{k}} \\
\leq h_{r}^{-1} \sum_{k \in I_{r}} \max \left(K_{h}, K_{H}\right)+h_{r}^{-1} \sum_{k \in I_{r}} f(\varepsilon)^{p_{k}} \\
\leq \max \left(K_{h}, K_{H}\right) h_{r}^{-1}\left|\left\{k \in I_{r}:\left|\Delta_{v}^{\alpha} x_{k}-L\right| \geq \varepsilon\right\}\right|+\max \left(f(\varepsilon)^{h}, f(\varepsilon)^{H}\right)
\end{gathered}
$$

Hence $x \in N_{\theta}\left(\Delta_{v}^{\alpha}, f, p\right)$. The following result is an immediate consequence of the Theorem 4.4 and Theorem 4.5.

Corollary 4.6. Let $f$ be bounded and $0<h=\inf p_{k} \leq p_{k} \leq \sup p_{k}=$ $H<\infty$. Then $S_{\theta}\left(\Delta_{v}^{\alpha}\right)=N_{\theta}\left(\Delta_{v}^{\alpha}, f, p\right)$.

\section{Conclusion}

Fractional order difference sequence space has been an active field of research during the recent times. Many authors have introduced different classes of difference sequence spaces of fractional order, obtained their $\alpha, \beta$ and $\gamma$ duals and matrix transformations. In this article we tend to generalize the findings of the previous authors using modulus function. We expect that the introduced notions and the results might be a reference for further studies in this field. For further studies one can investigate and generalize this results using multiplier sequences, sequence of modulus functions, etc. 


\section{Acknowledgement}

The author would like to express his gratitude to the anonymous referees for making necessary comments which make the paper more readable.

\section{References}

[1] H. Kizmaz, "On Certain Sequence Spaces", Canadian Mathematical Bulletin, vol. 24, no. 2, pp. 169-176, Jun. 1981, doi: 10.4153/CMB-1981-027-5.

[2] M. Et and R. Colak, "On some generalized difference sequence spaces", Soochow Journal of Mathematics, vol. 21, no. 4, pp. 377-386, Oct. 1995. [On line]. Available: http://bit.ly/2yGK1P4

[3] M. Et and A. Esi, "On Köthe-Toeplitz duals of generalized difference sequence spaces", Bulletin of the Malaysian Mathematical Science Society (Second series), vol. 23, no. 1, pp. 25-32, 2000. [On line]. Available: http://bit.ly/2KhvMqx

[4] M. Et and M. Basarir, "On some new generalized difference sequence spaces", Periodica Mathematica Hungarica, vol. 35, no. 3, pp. 169-175, Dec. 1997, doi: 10.1023/A:1004597132128.

[5] E. Malkowsky and S. D. Parashar, "Matrix transformations in spaces of bounded and convergent difference sequences of order m", Analysis, vol. 17, no. 1, pp. 87-98, 1997, doi: 10.1524/anly.1997.17.1.87.

[6] R. Colak, "Lacunary strong convergence of difference sequences with respect to a modulus function", Filomat, vol. 17, pp. 9-14, 2003. [On line]. Available: http://bit.ly/2ZJD0sA

[7] C. Aydın and F. Başar, "Some new difference sequence spaces", Applied Mathematics and Computation, vol. 157, no. 3, pp. 677-693, Oct. 2004, doi: 10.1016/j.amc.2003.08.055.

[8] M. Mursaleen, "Generalized spaces of difference sequences," Journal of Mathematical Analysis and Applications, vol. 203, no. 3, pp. 738-745, Nov. 1996, doi: 10.1006/jmaa.1996.0409.

[9] C.. Bektaş, M. Et, and R. Çolak, "Generalized difference sequence spaces and their dual spaces", Journal of Mathematical Analysis and Applications, vol. 292, no. 2, pp. 423-432, Apr. 2004, doi: 10.1016/j.jmaa.2003.12.006.

[10] P. Baliarsingh, "Some new difference sequence spaces of fractional order and their dual spaces", Applied Mathematics and Computation, vol. 219, no. 18, pp. 9737-9742, May 2013, doi: 10.1016/j.amc.2013.03.073.

[11] P. Baliarsingh and S. Dutta, "A unifying approach to the difference operators and their applications", Boletim da Sociedade Paranaense de Matemática, vol. 33, no. 1, pp. 49-57, 2013, doi: 10.5269/bspm.v33i1.19884. 
[12] P. Baliarsingh and S. Dutta, "On the classes of fractional order difference sequence spaces and their matrix transformations", Applied Mathematics and Computation, vol. 250, pp. 665-674, Jan. 2015, doi: 10.1016/j.amc.2014.10.121.

[13] U. Kadak and P. Baliarsingh, "On certain Euler difference sequence spaces of fractional order and related dual properties", Journal of Nonlinear Sciences and Applications, vol. 8, no. 6, pp. 997-1004, Nov. 2015, doi: 10.22436/jnsa.008.06.10.

[14] H. Fast, "Sur la convergence statistique", Colloqium Mathematicum, vol. 2, no. 3-4, pp. 241-244, 1951. [On line]. Available: http://bit.ly/2M1DC9M

[15] I. Schoenberg, "The integrability of certain functions and related summability methods", The American Mathematical Monthly, vol. 66, no. 5, pp. 361-775, 1959, doi: 10.1080/00029890.1959.11989303.

[16] I. Maddox, "Paranormed sequence spaces generated by infinite matrices", Mathematical Proceedings of the Cambridge Philosophical Society, vol. 64, no. 2, pp. 335-340, Apr. 1968, doi: 10.1017/S0305004100042894.

[17] H. Nakano, "Concave modulars", Journal of the Mathematical Society of Japan, vol. 5, no. 1, pp. 29-49, 1953, doi: 10.2969/jmsj/00510029.

[18] I. Maddox, "Spaces of strongly summable sequences", The Quarterly Journal of Mathematics, vol. 18, no. 1, pp. 345-355, Jan. 1967, doi: 10.1093/qmath/18.1.345.

[19] W. Ruckle, "FK spaces in which the sequence of coordinate vectors is bounded", Canadian Journal of Mathematics, vol. 25, no. 5, pp. 973-978, Oct. 1973, doi: 10.4153/CJM-1973-102-9.

[20] I. Maddox, Elements of functional analysis. 2nd ed. Cambridge: Cambridge Univ. Press, 1989.

[21] U. Kadak, "Generalized lacunary statistical difference sequence spaces of fractional order", International Journal of Mathematics and Mathematical Sciences, vol. 2015, Article ID 984283, 6 pages, 2015, doi: $10.1155 / 2015 / 984283$.

[22] B. Tripathy and M. Et, "On generalized difference lacunary statistical convergence”, Studia Universitatis Babeş-Bolyai Mathematica, vol. 50, no. 1, pp. 119-130, Mar. 2015. [On line]. Available: http://bit.ly/2TdQaMk

[23] B. Tripathy and S. Mahanta, "On a class of generalized lacunary difference sequence spaces defined by Orlicz functions", Acta Mathematicae Applicatae Sinica, English Series, vol. 20, no. 2, pp. 231-238, Jun. 2004, doi: 10.1007/s10255-004-0163-1.

[24] B. Tripathy and A. Baruah, "Lacunary statistically convergent and lacunary strongly convergent generalized difference sequences of fuzzy real numbers", Kyungpook Mathematical Journal, vol. 50, no. 4, pp. 565-574, 2010. [On line]. Available: http://bit.ly/33d71TP 
[25] B. Tripathy and P. Chandra, "On some generalized difference paranormed sequence spaces associated with multiplier sequence defined by modulus function", Analysis in Theory and Applications, vol. 27, no. 1, pp. 21-27, Mar. 2011, doi: 10.1007/s10496-011-0021-y.

[26] B. Tripathy and H. Dutta, "On some lacunary difference sequence spaces defined by a sequence of Orlicz functions and q-lacunary $\Delta \mathrm{n}$ m-statistical convergence", Analele Stiintifice ale Universitatii Ovidius, Seria Matematica, vol. 20, no. 1, pp. 417-430, 2012. [On line]. Available: http://bit.ly/2Kfkzqx

[27] B. Tripathy, B. Hazarika and B. Choudhary, "Lacunary I-convergent sequences”, Kyungpook Mathematical Journal, vol. 52, no. 4, pp. 473-482, 2012. [On line]. Available: http://bit.ly/2yEvinR

[28] M. Et, "Generalized Cesàro difference sequence spaces of non-absolute type involving lacunary sequences", Applied Mathematics and Computation, vol. 219, no. 17, pp. 9372-9376, May 2013, doi: 10.1016/j.amc.2013.03.039.

[29] S. Dutta and P. Baliarsingh, "A note on paranormed difference sequence spaces of fractional order and their matrix transformations", Journal of the Egyptian Mathematical Society, vol. 22, no. 2, pp. 249-253, Jul. 2014, doi: 10.1016/j.joems.2013.07.001.

[30] S. Demiriz and O. Duyar, "On some new difference sequence of fractional order", 2014, arXiv:1408.1269v1.

[31] J. Fridy and C. Orhan, "Lacunary statistical convergence", Pacific Journal of Mathematics, vol. 160, no. 1, pp. 43-51, Sep. 1993, doi: 10.2140/pjm.1993.160.43.

[32] S. Pehlivan and B. Fisher, "On some sequence spaces", Indian Journal of Pure and Applied Mathematics, vol. 25, no. 10, pp. 1067-1071, Oct. 1994. [On line]. Available: http://bit.ly/2YEmSHK

[33] H. Furkan, "On some $\lambda$ difference sequence spaces of fractional order", Journal of the Egyptian Mathematical Society, vol. 25, no. 1, pp. 37-42, Jan. 2017, doi: 10.1016/j.joems.2016.06.005.

[34] A. Freedman, J. Sember and M. Raphael, "Some Cesàro-type summability spaces", Proceedings of the London Mathematical Society, vol. s3-37, no. 3, pp. 508-520, Nov. 1978, doi: 10.1112/plms/s3-37.3.508. 